\section{Nauplius}

The Journal OF The Brazilian Crustacean Society

\author{
e-ISSN 2358-2936 \\ www.scielo.br/nau \\ www.crustacea.org.br
}

\title{
Neotropical freshwater crabs (Decapoda: Pseudothelphusidae) shred leaves
}

\author{
Carol Yang ${ }^{1,2}$ (D) orcid.org/0000-0002-5760-3262 \\ Ingo S. Wehrtmann ${ }^{3,4}$ (D) orcid.org/0000-0002-6826-7938 \\ Seth J. Wenger ${ }^{1,2}$ (D) orcid.org/0000-0001-7858-960X \\ Amanda T. Rugenski1',2 (D) orcid.org/0000-0001-8269-5632
1 Odum School of Ecology, University of Georgia. Athens, GA 30602, U.S.A. CY Email: carolyang214@gmail.com SJW Email: swenger@uga.edu ATR Email: atrugenski@uga.edu

2 River Basin Center, University of Georgia. Athens, GA30602, U.S.A.

3 Centro de Investigación en Ciencias del Mar y Limnología (CIMAR), Universidad de Costa Rica. San José, Costa Rica

4 Museo de Zoología, Escuela de Biología, Universidad de Costa Rica. San José, Costa Rica

ISW Email: ingo.wehrtmann@ucr.ac.cr

ZOOBANK: http://zoobank.org/urn:lsid:zoobank.org:pub:AF874CD4-A7A0-4F1D8109-E49990BFA55C

\section{ABSTRACT}

Freshwater crabs are macroconsumers that are commonly found in Neotropical headwater streams that may play a key role in energy flow and nutrient cycling in detrital food webs. Although studies have examined the feeding habits of trichodactylid crabs, little is known of this behavior in pseudothelphusid species, and specifically whether they actually consume leaf material. We conducted three nine-day laboratory trials with pseudothelphusid crabs (Ptychophallus tumimanus (Rathbun, 1898)) and leaves (Koanophyllon pittieri) to investigate whether crabs shred leaves. We hypothesized that leaf mass loss would be faster with crabs present relative to control tanks with only leaves. Leaf mass loss was significantly higher $(\mathrm{p}<0.001)$ in tanks with crabs $(0.49 \pm 0.07 \mathrm{~g}$, mean $\pm 1 \mathrm{SD})$ compared to control tanks $(0.31$ $\pm 0.05 \mathrm{~g}$ ). We observed crabs manipulating, shredding, and consuming leaves, with leaf fragments and egesta present in tanks with crabs but not in control tanks. Their consumption and egestion activity may affect nutrient availability and transformation by stimulating microbial activity during leaf breakdown and converting coarse particulate organic matter (CPOM) to fine particulate organic matter (FPOM). Therefore, freshwater crabs need to be considered when studying energy flow and nutrient cycling in detrital food webs of Neotropical headwater streams.

\section{KEYWORDS}

Leaf breakdown, Decapod macroconsumers, Shredders, Ptychophallus tumimanus, Costa Rica 


\section{INTRODUCTION}

Macroinvertebrates that shred leaves play an important role in nutrient cycling in detrital food webs (Wallace and Webster, 1996; Vanni, 2002). Decapod macroconsumers, such as crabs and shrimps, increase rates of leaf breakdown in some tropical streams (Crowl et al., 2001; Mancinelli et al., 2013), but it is unclear whether the increased leaf breakdown rates are due to bioturbation and foraging habits or direct consumption of leaves (Landeiro et al., 2008; Moulton et al., 2010). Although crabs have been suggested to be important shredders in tropical streams (Hill and O'Keefe, 1992; Moss, 2005; Yang et al., 2020) and plant material has been identified in gut content analyses (Pirela and Rincón, 2013; Williner et al., 2014), few studies have directly examined if and how crabs shred and consume leaves. One exception is the study of Costa et al. (2016), which found that adult Trichodactylus fluviatilis Latreille, 1828 have the potential to feed on both leaf litter and caddisfly (Triplectides sp.) larvae during laboratory trials. If land use change or other anthropogenic activities in the tropics (see Wehrtmann et al., 2016) reduce crab populations, there would be implications for the food web dynamics and ecosystem functions of these streams.

Pseudothelphusidae and Trichodactylidae are the two families of freshwater crabs found in the Neotropics (Cumberlidge et al., 2014). Recent feeding ecology studies in the Neotropics have focused on trichodactylid crabs in South America and have found crab gut contents with predominantly allochthonous plant debris, as well as prey items such as macroinvertebrate larvae and fish (e.g., Pirela and Rincón, 2013; Williner et al., 2014). There have been fewer studies that have characterized the feeding habits of pseudothelphusid crabs; while Wehrtmann et al. (2019) documented the role of Ptychophallus uncinatus Campos and Lemaitre, 1999 as a predator of an insect larva and amphibians, to our knowledge, no studies have directly tested whether pseudothelphusid crabs shred and directly consume leaves. Here, we report on a series of three nine-day laboratory feeding trials in which we recorded the rate of leaf mass loss in treatments with and without pseudothelphusid crabs, and in which we visually documented crab feeding behavior. We hypothesized that crabs would directly shred and consume leaves and that there would be higher loss of leaf mass in tanks with crabs present.

\section{Material and Methods}

We conducted this study in Monteverde, Costa Rica, where pseudothelphusid crabs are the largest invertebrate macroconsumers in streams. Located near the continental divide of the Cordillera de Tilarán, streams in the Monteverde region include first- and second-order headwater tributaries of the Guacimal River that drains into the Gulf of Nicoya in the Pacific Ocean. Mean annual precipitation is 2700 $\mathrm{mm}$ (Guswa et al., 2007), with the majority of rainfall occurring during the wet season (May-October).

A laboratory leaf feeding experiment with crabs of the species Ptychophallus tumimanus (Rathbun, 1898) was carried out from 18 June to 17 July 2019 to quantify and observe effects of these decapods on leaves in a controlled environment. Crabs were manually collected from the Quebrada Máquina $\left(10.3113818^{\circ}-84.8081506^{\circ}\right)$, a first-order tributary of the Guacimal River near the town of Santa Elena, province of Puntarenas. We searched for crabs by turning over rocks in riffles and runs and emergent rocks located on the stream banks. Crabs were transported to plastic aquaria tanks $(27 \mathrm{~cm} \mathrm{x} 17 \mathrm{~cm}$ $\mathrm{x} 18 \mathrm{~cm}$ ) in a laboratory setting. We measured crab carapace width (CW; measured across the carapace at its widest point) and carapace length (CL; measured along the midline, from the frontal to the posterior margin) with calipers, and recorded live wet mass $( \pm$ $0.01 \mathrm{~g}$ ). All crabs in the experiment had a similar CW, $\mathrm{CL}$, and wet mass (Tab. 1). Five crabs were males and three were females. Crabs were marked prior to the experiment to be able to quantify individual mass change over the duration of each experiment. We labeled crabs by attaching numbers written on Rite in the Rain paper ( $25 \mathrm{~mm}^{2}$ each) to the middle of each carapace using a drop of Loctite super glue and applied quick-dry clear nail polish on top of each tag. This rapid marking method is not associated with mortality or significant stress (Yang et al., 2020). Crabs from the experiment were identified to species using Magalhães et al. (2015). At the end of the study, 
we preserved a subset of crabs in $95 \%$ ethanol and deposited voucher specimens from the experiment at the Museo de Zoología, Universidad de Costa Rica; remaining crabs were released back to the stream.

Table 1. Mean with standard deviation $( \pm S D)$, minimum and maximum of carapace width (CW), carapace length (CL), and wet weight of crabs (Ptychophallus tumimanus) in the experiments.

\begin{tabular}{lcccc}
\hline & Mean $( \pm$ SD) & Minimum & Maximum & $\mathbf{N}$ \\
\hline CW $(\mathrm{mm})$ & $26 \pm 2.8$ & 23 & 29 & 8 \\
CL $(\mathrm{mm})$ & $19 \pm 1.2$ & 17 & 20 & 8 \\
Wet weight $(\mathrm{g})$ & $4.49 \pm 0.81$ & 3.03 & 5.66 & 8 \\
\hline
\end{tabular}

Each of eight tanks was filled with unfiltered stream water to a height of $8 \mathrm{~cm}$ to allow for natural microbial colonization of leaves. We added a consistent amount of cobble substrate from the stream to each tank to provide refugia for the crabs. Green leaves from the common subcanopy tree Koanophyllon pittieri (Asteraceae; Haber et al., 2000) were picked directly from trees bordering the stream where we collected crabs. We did not use fallen leaves to minimize variability and because leaves are often displaced by wind or rain prior to natural abscission (Colón-Gaud et al., 2008) and green K. pittieri leaves are found in leaf packs in the stream (C. Yang, pers. obs.). After drying the leaves for $72 \mathrm{~h}$ at $40^{\circ} \mathrm{C}$, we weighed them to obtain initial dry mass before adding $1.03 \pm 0.02$ $\mathrm{g}$ of whole leaves to each tank. Leaf incubation in stream water began after the dry leaves were added to the tanks at the start of the experiment. Four of the tanks each had two similar-sized crabs (CW 23-29 $\mathrm{mm}$ ) and four had no crabs (control). Treatments were randomly assigned. The control tanks contained leaves but no crabs, which allowed us to estimate leaf mass loss due to leaching and microbial processing. Deploying two crabs in a tank permitted us to mimic natural densities of crabs in the Quebrada Máquina (C. Yang, unpublished data). Previous experiments confirmed that two crabs of similar sizes can use cobble for cover in the same tank and do not engage in direct aggression, but rather, passively move into different crevices or cobble surfaces (C. Yang, pers. obs.). All crabs had at least $24 \mathrm{~h}$ of gut clearance before the start of the experiment with the exception of one crab that molted just before the start of the experiment and was replaced with a crab brought directly from the field.

We maintained all tanks in controlled laboratory conditions with aerated stream water and natural ambient photoperiod. Mean water temperature in the tanks was $20.48 \pm 1.64{ }^{\circ} \mathrm{C}$ and ranged between 17.76 and $25.22^{\circ} \mathrm{C}$. After nine days, the remaining leaf material was collected from each tank, dried at $40^{\circ} \mathrm{C}$ for $72 \mathrm{~h}$, and weighed to determine post-experiment leaf mass (Benfield et al., 2017). We measured the wet mass of crabs after each experimental trial. We repeated the experiment a total of three times with the same procedures and the same crabs, allowing at least $24 \mathrm{~h}$ of gut clearance between each experiment, with a total of $\mathrm{N}=12$ for each treatment.

The leaf mass loss for each treatment was calculated by assessing the difference between initial and postexperiment leaf dry mass. A two-sample t-test was applied to compare the mean difference in leaf mass loss between tanks with and without crabs. We calculated the amount of leaf material processed per gram of crab wet mass and the amount of leaf material consumed per crab per day. We quantified the mean mass change of crabs over each nine-day study period and the percent change in mass based on average initial wet mass. We also assessed whether the use of the same crabs in the three experimental trials affected the leaf mass loss results with a randomintercept model using the lme4 package in R. Results from the random-intercept model accounting for the non-independence of crabs between experiments were compared with t-test results. All statistical analyses were performed in R statistical software version 3.4.4 (R Core Team, 2018).

\section{Results}

After nine days, the leaf mass loss was higher in the tanks with crabs $(0.49 \pm 0.07 \mathrm{~g}$, mean $\pm 1 \mathrm{SD})$ than tanks without crabs $(0.31 \pm 0.05 \mathrm{~g})$, a statistically significant difference of $0.18 \mathrm{~g}$ (95\% CI: 0.13-0.23 $\mathrm{g}), \mathrm{t}(26)=7.36, \mathrm{p}<0.001$. We found identical results with the random-intercept model that accounted for repeated observations, so for simplicity we just report the t-test results. At the end of the laboratory experiments, there was $52.9 \%$ of the initial leaf mass 


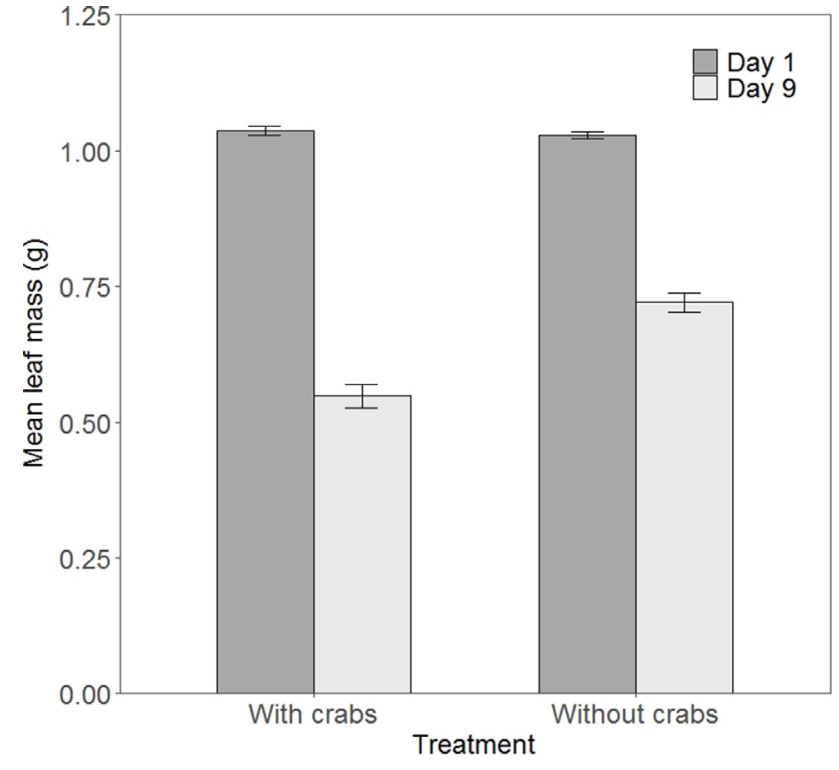

Figure 1. Mean leaf mass remaining in tanks with and without (i.e., leaves only) crabs, Ptychophallus tumimanus, on days one and nine. Depicted are means with standard error $( \pm S E)$. There was a statistically significant difference of $0.18 \mathrm{~g}$ (95\% CI: $0.13-0.23$ $\mathrm{g})$ of leaf mass loss in tanks with and without crabs $(\mathrm{t}(26)=$ 7.36, $\mathrm{p}<0.001)$. remaining in tanks with crabs compared to $70.1 \%$ remaining in control tanks (Fig. 1). The amount of leaf material processed was equivalent to $0.02 \mathrm{~g}$ per gram of crab wet mass over nine days and $0.01 \mathrm{~g}$ of leaf consumed per crab per day.

We visually observed and video-recorded crabs actively shredding and ingesting leaves (Fig. 2, Video S1), although all such observations occurred during the latter part of each trial; no crab consumption of leaves was recorded during the first three days of any trial. In tanks with crabs, the majority of the remaining leaf mass was composed of small fragments (Figs. 3A, $4 \mathrm{~A}$ ), whereas in control tanks, the $K$. pittieri leaves were still intact after nine days (Fig. 3B). We also observed crab egesta in the tanks (Fig. 4B), providing further evidence that leaves were consumed. None of the crabs molted during these experiments, so there was no change in CW, CL, or wet mass.

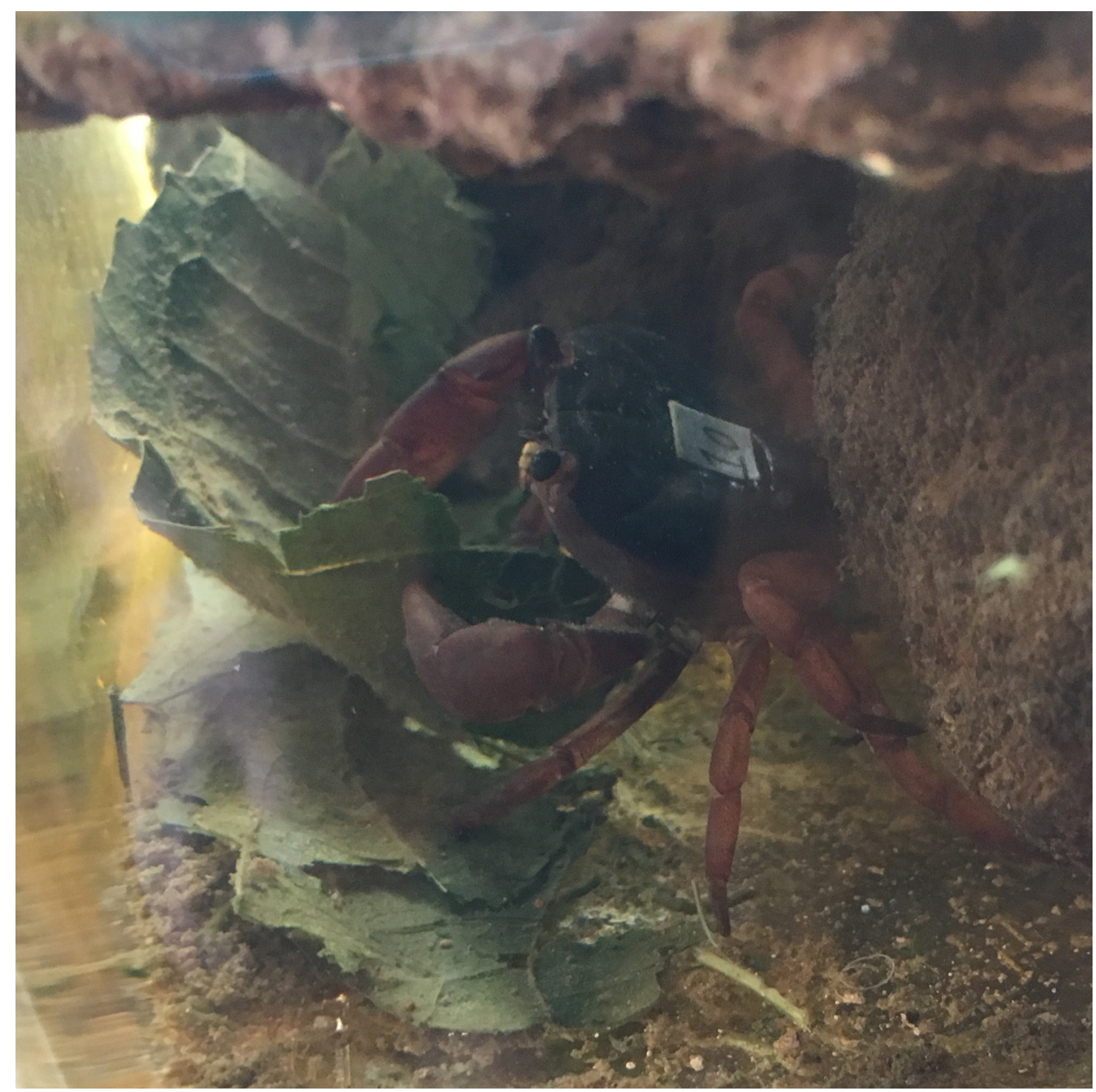

Figure 2. Pseudothelphusid crab (Ptychophallus tumimanus) consuming leaf material in a tank. 


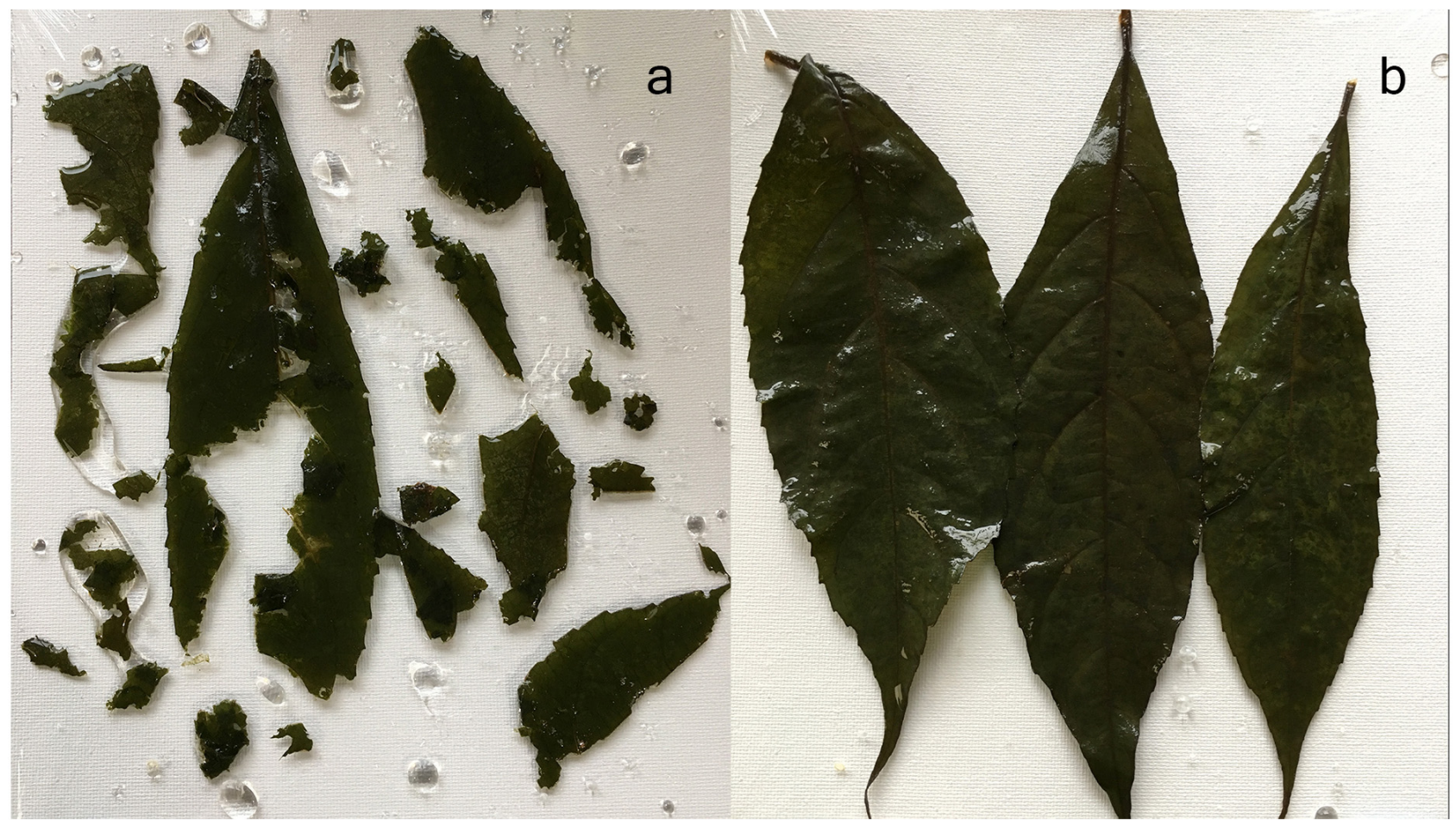

Figure 3. Koanophyllon pittieri leaves in tanks after nine days of incubation: A, Leaves in tanks with crabs (Ptychophallus tumimanus); B, Leaves in control tank (no crabs).

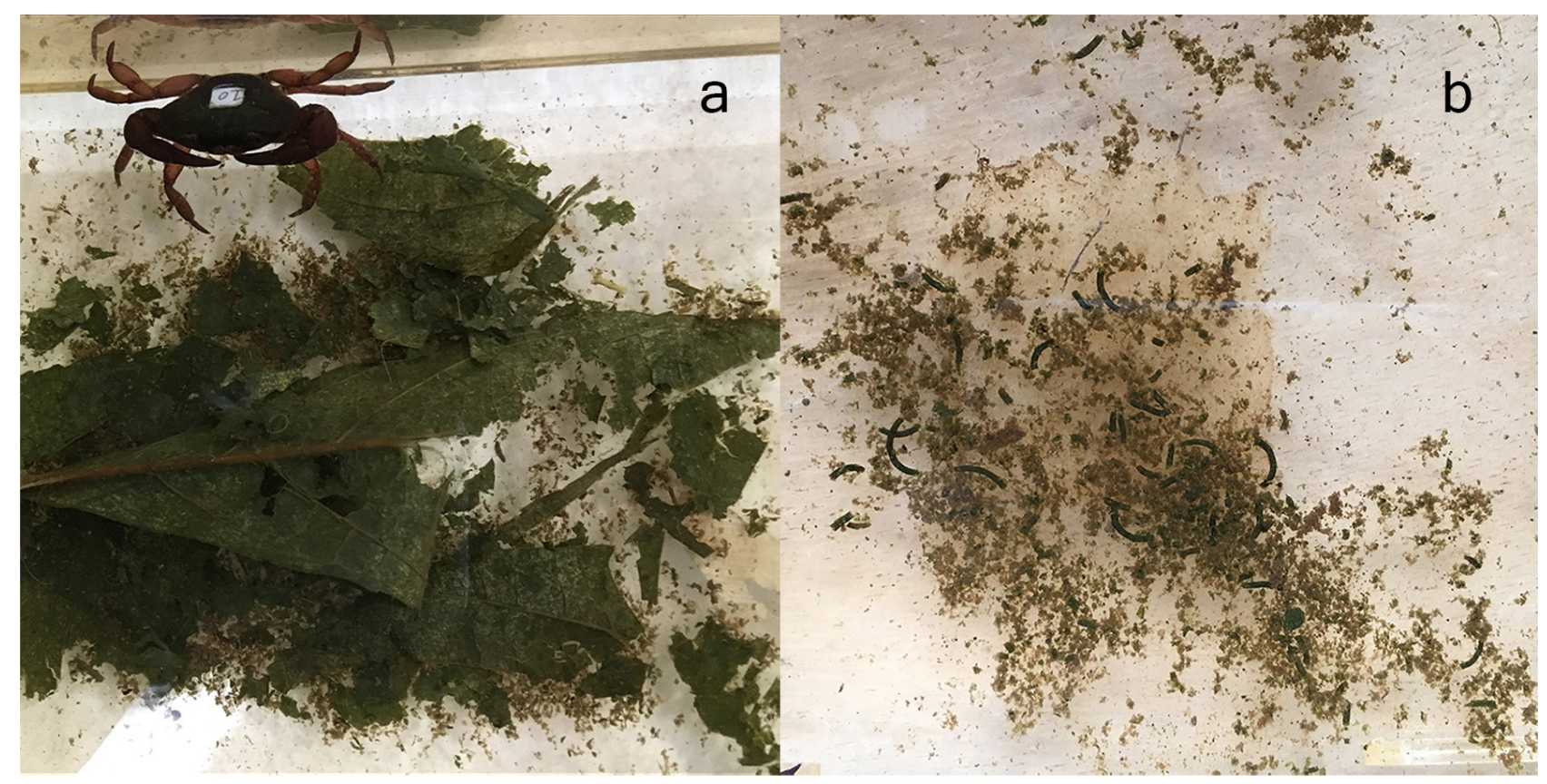

Figure 4. Tank with crabs (Ptychophallus tumimanus) after nine days: A, Crab with remaining leaf mass in tank; B, Crab egesta in tank.

\section{Discussion}

We found clear evidence that $P$. tumimanus crabs increase leaf breakdown rates through direct consumption of leaves. We observed crabs actively shredding pieces of leaves and tearing strands of leaf fibers for consumption in the tanks. Costa et al. (2016) also reported crab (T. fluviatilis) manipulation of leaves with chelipeds, though they did not observe 
a significant difference in leaf decay rates across treatments (crabs with and without the caddisfly shredder Triplectides sp.). For their 10-day feeding trials, Costa et al. (2016) used Miconia chartacea and Hoffmannia dusenii leaves that were conditioned for 15 days prior to the experiment. In contrast, the $K$. pittieri leaves that we used were not conditioned prior to starting each experiment but were soft after nine days of incubation in the tanks.

According to Costa et al. (2016), fine particulate organic matter (FPOM) was the primary food category found in guts of T. fluviatilis that were fed leaves in laboratory trials. Crab manipulation of food particles with their chelipeds, mouthparts, and the gastric mill in their digestive structures likely results in plant matter reaching their guts in the form of FPOM (Collins et al., 2007; Alves et al., 2010). Pirela and Rincón (2013) conducted gut content analyses of the trichodactylid crab Bottiella niceforei (Schmitt and Pretzmann, 1968) and found that plant detritus was the most frequent item that occurred in crab guts. In subtropical streams, Williner et al. (2014) also found allocthonous plant material to be an important component of gut contents in Trichodactylus kensleyi Rodríguez, 1992 crabs. Our study provides evidence of the mechanisms (e.g., grasping and tearing leaves with their chelipeds) that crabs use to consume leaves.

Shredding macroinvertebrates affect stream ecosystems through multiple pathways, including increased downstream transport of particulate nutrients (Wallace and Webster, 1996). As crabs consumed leaf fragments during our feeding trials, they added small pieces of leaves to the water column as coarse particulate organic matter (CPOM) and FPOM. Therefore, shredding and leaf consumption by crabs may affect the availability of CPOM and FPOM for macroinvertebrates such as filterers and collector-gatherers in Neotropical streams. In addition to leaf particles, egesta accumulated in the tanks with crabs as they consumed leaves, and we presume that crabs also excreted nitrogenous waste. Nutrient excretion and egestion by animals affect resource availability for other organisms in streams (Vanni, 2002; McManamay et al., 2011; Atkinson et al., 2017) and can enhance microbial activity on leaves and other detritus. However, we did not measure nutrient concentrations as part of this study.
Comparison of crab leaf consumption rates to those of other shredding organisms is challenging because of differences in methodologies employed across feeding studies (e.g., leaf conditioning periods, use of leaf discs or entire leaves, varying leaf types, single- or mixed-leaf species, etc.). Leaf consumption rates from laboratory trials may also be higher than feeding rates in natural environments due to limited food resource options during experiments. We were not able to compare $P$. tumimanus leaf consumption rates to other freshwater crabs as most diet studies have focused on gut content analyses (e.g., Pirela and Rincón, 2013; Costa et al., 2016). However, relative to other feeding studies, the rate of leaf consumption per crab from our study - $9.99 \mathrm{mg} \mathrm{crab}^{-1} \mathrm{~d}^{-1}-$ is higher than that reported for many other aquatic invertebrates. Crowl et al. (2006) reported a rate of leaf consumption of $3.80 \mathrm{mg} \mathrm{shrimp}^{-1} \mathrm{~d}^{-1}$ for shrimp (Xiphocaris elongata (Guérin-Méneville, 1855 in Guérin-Méneville, 1855-1856)) fed Manilkara bidentata leaves. Herbst (1982) reported mean consumption values from 1.63 to $3.91 \mathrm{mg}^{2}$ animal ${ }^{-1} \mathrm{~d}^{-1}$ for cranefly larvae (Tipula abdominalis Say, 1823) and 0.05 to $0.89 \mathrm{mg}$ animal $^{-1} \mathrm{~d}^{-1}$ for amphipods (Gammarus pseudolimnaeus Bousfield, 1958). The biomass and abundance of different aquatic invertebrates, however, ranges widely and the ecosystem-level effects of leaf processing by different shredder taxa depends on their population biomass and production.

Different shredder taxa have varying feeding rates and mechanisms for shredding leaves. Given their large body size and the ways in which crabs manipulate, shred, and consume leaves using their chelipeds and mouthparts, they may play an important role in converting leaf material into CPOM and FPOM. In addition, because $P$. tumimanus can reach relatively high densities (e.g., $\sim 4.7$ crabs/m of stream length in the Quebrada Máquina; C. Yang, unpublished data), the rates of leaf consumption we measured in this experiment suggest that $P$. tumimanus are an important component of energy flow and nutrient cycling in detrital food webs in Neotropical headwater streams.

The results from our experiment contrast with studies that have suggested that invertebrates are less important than microbes in detrital processing in tropical streams (e.g., Irons et al., 1994; Mathuriau 
and Chauvet, 2002). Tropical shredders may have been overlooked due to methodological reasons, especially because decapod macroconsumers can be difficult to sample using typical macroinvertebrate sampling techniques given their high mobility and large size (Dobson, 2004; Magana et al., 2012; Masese et al., 2014). Exclusion of decapods from macroinvertebrate analyses can be problematic in the tropics because they can be abundant and represent a large proportion of the macroinvertebrate biomass and production (Crowl et al., 2001; Moss, 2005; Greathouse and Pringle, 2006; Pirela and Rincón, 2013). Further studies are needed to investigate whether other species of freshwater crabs, in addition to P. tumimanus, also consume leaves and how rates of leaf consumption may vary among crab species and of different size classes.

Leaf litter breakdown is important not only for headwater streams driven by allochthonous resources, but also for downstream transport of nutrients and energy. While our study reports a small data set, the effect of $P$. tumimanus on leaf breakdown was clear and had not been previously quantified. Our results suggest that crabs can play an important role in detrital processing and should be included in future studies that quantify tropical shredder communities and leaf breakdown processes.

\section{ACKNOWLEDGEMENTS}

We thank Wilbert J. Jiménez Hernández and Giulia Sturmo for their help with data collection. We are grateful to the Van den Akker family for providing field site access and the Monteverde Institute for providing laboratory facilities. We thank Fresia Villalobos-Rojas (CIMAR, Universidad de Costa Rica) for her assistance with crab identification and Willow Zuchowski and Bill Haber for helping with plant identification and information. We appreciate Zachary Butler for helping with the video. Our manuscript was improved by suggestions from Dr. Mary Freeman and two anonymous reviewers.

\section{Supplemental Material}

Video S1. Video of crabs (Ptychophallus tumimanus) shredding and consuming leaves. Available at https://vimeo.com/385357347

\section{References}

Alves, S.T.M.; Abrunhosa, F.A. and Lima, J.d.F. 2010. Foregut morphology of Pseudothelphusidae and Trichodactylidae (Decapoda: Brachyura) from northeastern Pará, Brazil. Zoologia, 27: 228-244.

Atkinson, C.L.; Capps, K.A.; Rugenski, A.T. and Vanni, M.J. 2017. Consumer-driven nutrient dynamics in freshwater ecosystems: from individuals to ecosystems. Biological Reviews, 92: 2003-2023.

Benfield, E.F.; Fritz, K.M. and Tiegs, S.D. 2017. Leaf-litter breakdown. p. 71-82. In: G. Lamberti and F.R. Hauer (eds), Methods in Stream Ecology ( $3^{\text {rd }}$ ed.). Cambridge, MA, Academic Press.

Collins, P.; Williner, V. and Giri, F. 2007. Trophic relationships in crustacean decapods of a river with a floodplain. p. 59-86. In: M.T.E. Ashraf (ed), Predation in Organisms. Springer, Berlin, Heidelberg.

Colón-Gaud, C.; Peterson, S.D.; Whiles, M.R.; Kilham, S.S.; Lips, K.R. and Pringle, C.M. 2008. Allochthonous litter inputs, organic matter standing stocks, and organic seston dynamics in upland Panamanian streams: Potential effects of larval amphibians on organic matter dynamics. Hydrobiologia, 603: 301-312.

Costa, L.; Kiffer Jr., W.; Casotti, C.; Rangel, J. and Moretti, M. 2016. Influence of Trichodactylus fluviatilis on leaf breakdown in streams: Understanding the role of freshwater crabs in detritus-based food webs. Zoological Studies, 55: 54.

Crowl, T.A.; McDowell, W.H.; Covich, A.P. and Johnson, S.L. 2001. Freshwater shrimp effects on detrital processing and nutrients in a tropical headwater stream. Ecology, 82: 775-783.

Crowl, T.A.; Welsh, V.; Heartsill-Scalley, T. and Covich, A.P. 2006. Effects of different types of conditioning on rates of leaf-litter shredding by Xiphocaris elongata, a Neotropical freshwater shrimp. Journal of the North American Benthological Society, 25: 198-208.

Cumberlidge, N.; Alvarez, F. and Villalobos, J.L. 2014. Results of the global conservation assessment of the freshwater crabs (Brachyura, Pseudothelphusidae and Trichodactylidae): The Neotropical region, with an update on diversity. Zookeys, 457: 133-157.

Dobson, M. 2004. Freshwater crabs in Africa. Freshwater Forum, 21:3-26.

Guswa, A.J.; Rhodes, A.L. and Newell, S.E. 2007. Importance of orographic precipitation to the water resources of Monteverde, Costa Rica. Advances in Water Resources, 30: 2098-2112.

Greathouse, E.A. and Pringle, C.M. 2006. Does the river continuum concept apply on a tropical island? Longitudinal variation in a Puerto Rican stream. Canadian Journal of Fisheries and Aquatic Sciences, 63: 134-152.

Haber, W.A.; Zuchowski, W. and Bello, E. 2000. An introduction to cloud forest trees: Monteverde, Costa Rica ( $2^{\text {nd }}$ ed.). Monteverde, Costa Rica: Mountain Gem Publications.

Herbst, G.N. 1982. Effects of leaf type on the consumption rates of aquatic detritivores. Hydrobiologia, 89: 77-87.

Hill, M.P. and O'Keefe, J.H. 1992. Some aspects of the ecology of the freshwater crab (Potamonautes perlatus Milne Edwards) in the upper reaches of the Buffalo River, eastern Cape Province, 
South Africa. South African Journal of Aquatic Sciences, 18: $42-50$.

Irons, J.G.; Oswood, M.W.; Stout, R.J. and Pringle, C.M. 1994. Latitudinal patterns in leaf litter breakdown: is temperature really important? Freshwater Biology, 32: 401-411.

Landeiro, V.L.; Hamada, N. and Melo, A.S. 2008. Responses of aquatic invertebrate assemblages and leaf breakdown to macroconsumer exclusion in Amazonian "terra firme" streams. Fundamental and Applied Limnology, 172: 49-58.

Magalhães, C.; Wehrtmann, I.S.; Lara, L.R. and Mantelatto, F.L. 2015. Taxonomy of the freshwater crabs of Costa Rica, with a revision of the genus Ptychophallus Smalley, 1964 (Crustacea: Decapoda: Pseudothelphusidae). Zootaxa, 3905: 301-344.

Magana, A.M.; Dobson, M. and Mathooko, J.M. 2012. Modifying Surber sampling technique increases capture of freshwater crabs in African upland streams. Inland Waters, 2: 11-15.

Mancinelli, G.; Sangiorgio, F. and Scalzo, A. 2013. The effects of decapod crustacean macroconsumers on leaf detritus processing and colonization by invertebrates in stream habitats: A meta-analysis. International Review of Hydrobiology, 98: 206-216

Masese, F.O.; Kitaka, N.; Kipkemboi, J.; Gettel, G.M.; Irvine, K. and McClain, M.E. 2014. Macroinvertebrate functional feeding groups in Kenyan highland streams: Evidence for a diverse shredder guild. Freshwater Science, 33: 435-450.

Mathuriau, C. and Chauvet, E. 2002. Breakdown of leaf litter in a neotropical stream. Journal of the North American Benthological Society, 21: 384-396.

McManamay, R.A.; Webster, J.R.; Valett, H.M. and Dolloff, C.A. 2011. Does diet influence consumer nutrient cycling? Macroinvertebrate and fish excretion in streams. Journal of the North American Benthological Society, 30: 84-102.

Moss, B. 2005. Rapid shredding of leaves by crabs in a tropical African stream. Verhandlungen der Internationalen Vereinigung für theoretische und angewandte Limnologie, 29: 147-150.

Moulton, T.P.; Magalhães-Fraga, S.A.; Brito, E.F. and Barbosa, F.A. 2010. Macroconsumers are more important than specialist macroinvertebrate shredders in leaf processing in urban forest streams of Rio de Janeiro, Brazil. Hydrobiologia, 638: 55-66.
Pirela, R. and Rincón, J. 2013. Dieta del cangrejo dulceacuícola Bottiella niceforei (Schmitt \& Pretzmann, 1968) (Decapoda: Trichodactylidae) y su relación con el procesamiento de la materia orgánica en una corriente intermitente del noroeste de Venezuela. Latin American Journal of Aquatic Research, 41: 696-706.

R Core Team. 2018. R: A language and environment for statistical computing. Vienna, Austria: R Foundation for Statistical Computing. Available at http:/ / www.R-project.org/.Accessed on 10 August 2019.

Rathbun, M.J. 1898. A contribution to a knowledge of the fresh-water crabs of America. - The Pseudothelphusinae. Proceedings of the United States National Museum, 21: 507-535.

Vanni, M.J. 2002. Nutrient cycling by animals in freshwater ecosystems. Annual Review of Ecology and Systematics, 33: 341-370.

Wallace, J.B. and Webster, J.R. 1996. The role of macroinvertebrates in stream ecosystem function. Annual Review of Entomology, 41: 115-139.

Wehrtmann, I.S.; Ramírez, A. and Pérez-Reyes, O. 2016. Freshwater decapod diversity and conservation in Central America and the Caribbean. p. 267-301. In: T. Kawai and N. Cumberlidge (eds), A Global Overview of the Conservation of Freshwater Decapod Crustaceans. Cham, Springer International Publishing AG.

Wehrtmann, I.S.; Hernández-Díaz, D. and Cumberlidge, N. 2019. Freshwater crabs as predators and prey: the case of Ptychophallus uncinatus Campos and Lemaitre, 1999 (Brachyura, Pseudothelphusidae) from Costa Rica, Central America. Latin American Journal of Aquatic Research, 47: 18-26.

Williner, V.; Carvalho, D.A. and Collins, P.A. 2014. Feeding spectra and activity of the freshwater crab Trichodactylus kensleyi (Decapoda: Brachyura: Trichodactylidae) at La Plata basin. Zoological Studies, 53: 71-79.

Yang, C.,; Wenger, S.J.; Rugenski, A.T.; Wehrtmann, I.S.; Connelly, S. and Freeman, M.C. 2020. Freshwater crabs (Decapoda: Pseudothelphusidae) increase rates of leaf breakdown in a neotropical headwater stream. Freshwater Biology, doi.org/10.1111/fwb.13524 